\title{
Fricative Computing
}

Let's bring friction back into computing.

M

ARIE DE RABUTIN-CHANTAL, marquise de Sévigné, was a $17^{\text {th }}$ century French Parisian aristocrat, remembered for her 30-year-long correspondence with her Provenceresiding daughter. Over a thousand of their letters have been preserved and published in the $18^{\text {th }}$ century. They are considered a treasure of French literature. The time gap-two weeksbetween the mother's letters and her daughter's replies intensified the mother's worries, longings, and anxieties, which are vividly reflected in her letters.

It is difficult to imagine such correspondence today. The marquise and her daughter would be communicating frequently via email and text messages. The frequent exchanges would likely be quotidian and mundane, lacking the frisson that enriches the $17^{\text {th }}$ century letters. The emotional depth of these letters resulted from the difficulty of communication between mother and daughter. Eliminate that difficulty, and the emotions are eliminated as well. It is quite unlikely that future generations will cherish personal correspondence from the $21^{\text {st }}$ century.

Our discipline is dedicated to reducing friction. Latency must be eliminated, bandwidth must increase, and ubiquity should be universal. Our goal is to reduce the friction of computing and communication as much as possible. Facebook's CEO Mark Zuckerberg speaks of "frictionless sharing" as a goal. This reduction of friction has enabled the amazing world of the Internet and the Web we have created over the past 50 years, but should zero friction really be our goal?

One may dismiss my concern about letters-not-written as sentimental and anachronistic, but the effects of fric- tionless computing are quite serious. On May 6, 2010, at 2:45 P.M., the U.S. stock market declined steeply, with the Dow Jones Industrial Average plunging about 600 points in five minutes, following an earlier decline of more than 300 points on worries about the Greek debt crisis. As described in a just-published book by Neil Irwin, The Alchemists: Three Central Bankers and a World on Fire, the "flash crash" deeply shook the confidence of central bankers and had a dramatic impact on their decision making.

It was only a few months later that a joint report issued by the U.S. Securities and Exchange Commission and the Commodity Futures Trading Commission identified high-frequency trading as the cause of the crash. It turns out that much of the trading taking place today on financial markets is algorithmic, with software tools entering trading orders, using speed and frequency that cannot be matched by humans. Proponents of high-frequency trading say it helps make the markets more "liquid," but Thomas Peterffy, a high-frequency trading pioneer, recently argued that "Today's drive for speed has absolutely no social value."

Imagine a mechanical engineer who declares that her goal is to eliminate friction, period. We would view this

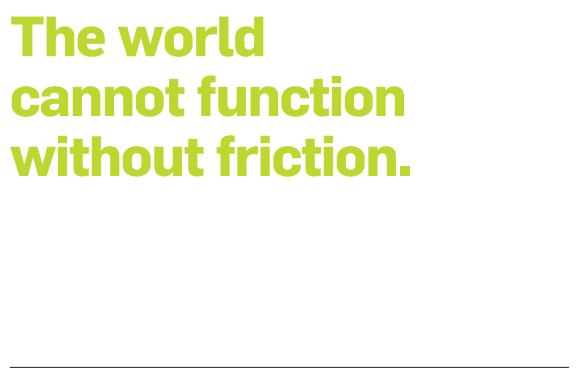

as insane. The world cannot function without friction. The goal should be to have the right amount of friction, in the right place, in the right time. Yet our discipline seems committed to the total elimination of friction in computing.

The adverse effects of frictionless computing are all around us. Email is the first example that comes to mind. It is simply too easy to send email messages, so we all send too many (I am famously guilty of this) and receive too many. It is also too easy to add recipients. We are simply drowning in email; with many articles bemoaning the "email tsunami" and "Pandora's inbox." An invention that was meant to free us from the overhead of paper communication ended up enslaving us electronically.

In almost every area touched by computing, we can see the symptoms of reduced friction. In a recent book by Dan Slater, Love in the Time of Algorithms, the author laments how online romance is threatening monogamy. "What if online dating makes it too easy to meet someone new?" he asks. "What if it raises the bar for a good relationship too high?" In essence, has online dating over-reduced the friction of dating?

The Greek philosopher Aristotle said "Anybody can become angrythat is easy, but to be angry with the right person, to the right degree, at the right time, for the right purpose, and in the right way - that is not easy." I feel the same about friction in computing. Reducing friction is easy, but having the right amount of friction, for the right application, in the right context, that is not easy, and is today a major challenge of computing.

Moshe Y. Vardi, EDITOR-IN-CHIEF 